\title{
A Literature Review of the Rocker-Bogie Suspension for the Planetary Rover
}

\author{
Jun Yang ${ }^{1, a}$, Mingming Dong ${ }^{1, b}$ and Jiatong $\mathrm{Ye}^{1, \mathrm{c}}$ \\ ${ }^{1}$ Beijing Institute of Technology,Beijing, China \\ a244810782@qq.com, bvdmm@bit.edu.cn, cijtye0519@163.com
}

Keywords: Rocker-bogie suspension, Extremely uneven roads, Rover, Mechanical design

\begin{abstract}
Suspension is divided into non-independent suspension and independent suspension. These two kinds of suspensions are widely used in general vehicles. General vehicles can travel on urban roads and highways. But they cannot travel on rough roads or extremely uneven roads. The rocker-bogie suspension is proposed to solve that problem. It is widely used in planetary rover. The purpose of this paper is to systematically compare the performance of these rovers. This paper review the different rocker-bogie suspensions designed by different countries and demonstrate their capability to improve the performance of the suspension of rovers. Various technologies in which different configurations, component combinations and mechanical designs are used to improve the performance of the suspension are also discussed in this paper.
\end{abstract}

\section{Introduction}

With the development of aerospace industry, planetary rovers have been designed to explore unknown planet. A planetary rover is a kind of autonomous vehicle, which can travel through the extremely rough road. The requirement of traveling through the extremely rough road challenges the conventional suspension system. The rocker-bogie suspension is a commendable solution to improve cross-country performance.

Robot Research Institute of Carnegie Mellon University developed the nomad rover [1]. The nomad rover has three different steering method to improve cross-country performance. The maximum moving speed of the nomad rover is $0.5 \mathrm{~m} / \mathrm{s}$. The speed is very low. The six-wheel rover is the main type and successful application in foreign countries. The United States, Russia and some European countries have made great achievements in the research of this type of vehicle. America is the world leader in the development of the six-wheel vehicle. In 1987, Jet Propulsion Laboratory(JPL) proposed the most representative of the rocker-bogie six wheeled Rover mobile system configuration, which have developed a variety of Rocky of Mars rover prototype, which has been successfully applied in Mars exploration [2][3]. Russia's research on wheel vehicles is at the forefront of the world. Three section series suspension configuration of the six wheel rocky which has been developed by Russian Vehicle Engineering Research Institute since 1980s is the representative of the results. Swiss Federal Institute of Technology and Swiss Autonomous Systems Lab have designed six shrimp rover [4][5]. The stability is good and the negotiation ability is strong. But the space of carrying in this vehicle is great limited and the suspension structure is complicated.

With the study of China's lunar exploration project, Many domestic universities and research institutes started to research rocker suspension of the vehicle [6]. National University of Defense Technology has designed a new type of folding and deployable suspension structure, which is called the double crank linkage torsion bar suspension. The rocker-bogie rover was developed by Harbin Institute of Technology. The auxiliary rocker arm can rotate around the hinge of the main rocker arm, and the left and the right sides of the main rocker arm can rotate around the differential mechanism to realize the two side differential, so that the 6 wheels are always simultaneously with the ground. However, there were few studies comparing these different kinds of planetary rover. The purpose of this paper is to systematically compare the performance of these rovers, including maneuverability, trafficability, stability, et al. The second performance is important because the 
rover should arrive anywhere on the planet even if the surface of plant is extremely uneven road surface. To realize this vision, the suspension of the planetary rover based on the conventional vehicle suspension should be improved to ensure the requirement of high trafficability and traveling at high speed.

In this paper, we investigate and review the different technologies and approaches, and demonstrate their capability to improve the performance of the suspension of rovers. Various technologies in which different configurations, component combinations and mechanical designs are used to improve the performance of the suspension are also discussed in this paper. For each rover, a brief description is first presented and then by reviewing the previous studies, the performance of the suspension of the rover is investigated. Finally, a comparison study between these rovers is carried out.

\section{The Rocker-Bogie Suspension for the Planetary Rover Designed by Soviets}

In 1970, Luna 17 carried Lunokhod 1 which is the world's first lunar exploration vehicle onto the lunar surface [7]. As shown in Figure 1 (a), Lunokhod 1 is about $756 \mathrm{~kg}$ and the body size is $4.42 \mathrm{~m} \times 2.15 \mathrm{~m} \times 1.92 \mathrm{~m}$. The structure of this vehicle is divided into upper and lower parts. The upper part is the sealed instrument compartment manufactured from magnesium alloy and the lower part is the automatic walking chassis which the eight wheels are independently drove. It can climb the 30-degree slope. It can also cross the $40-\mathrm{cm}$ barrier and the $60-\mathrm{cm}$ gully. the ground moving speed is $1 \mathrm{~km} / \mathrm{h}$ or $2 \mathrm{~km} / \mathrm{h}$.

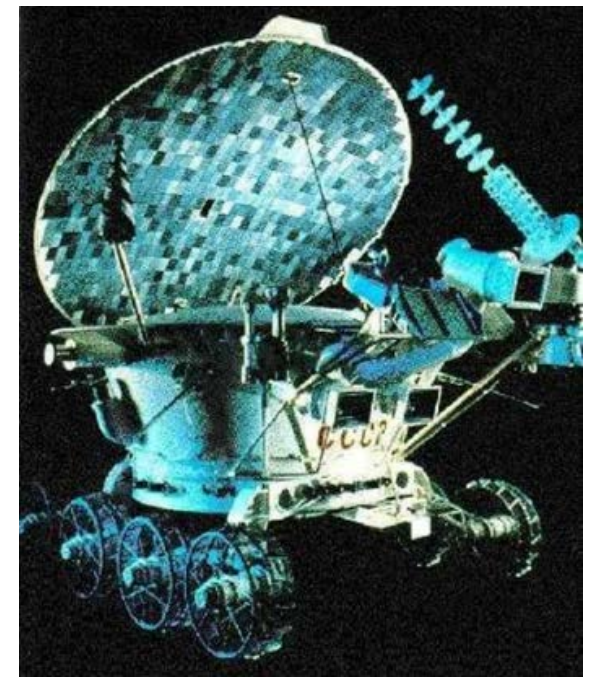

(a) Lunokhod 1

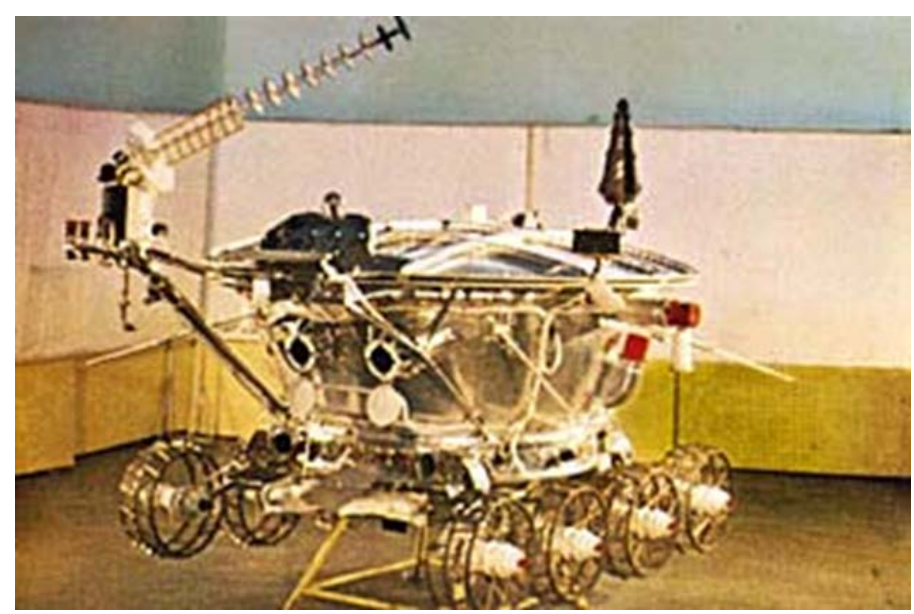

(b) Lunokhod 2

Fig.1. Two kinds of Lunokhod

The Lunokhod 2 was carried by the Luna 21 in 1973 and landed in the eastern part of the Moon [8][9]. As shown in Figure 1 (b), the configuration of the vehicle is similar to Lunokhod 1. However, the structure was improved, the speed of movement was increased, the scope of activities was bigger than the Lunokhod 1.

\section{The Rocker-Bogie Suspension for the Planetary Rover Designed by Swiss}

In 2002, Swiss Federal Institute of Technology and Automation Systems Laboratory (ASL) developed a prototype of six-wheel detection vehicle called shrimp [10]. The shrimp is about $3.1 \mathrm{~kg}$, which the front fork-parallelogram rocker suspension is used. As shown in Figure 2, the shrimp was climbing stairs. The stability of the shrimp is good and The trafficability of the shrimp is strong. But the space of carrying in this vehicle is great limited due to the limitation of the suspension structure. The suspension structure is also complicated. 


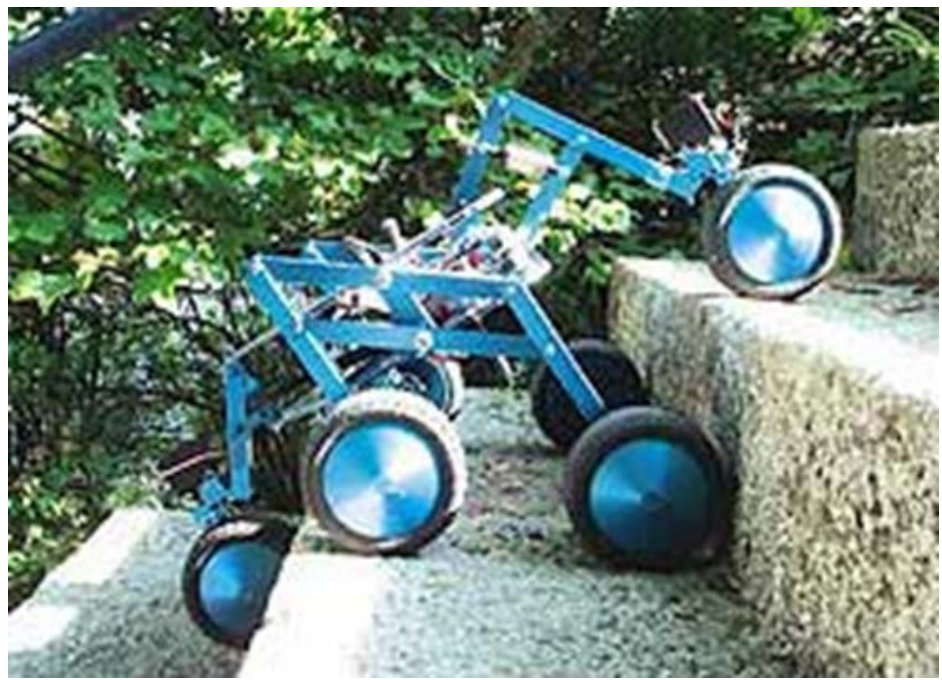

Fig. 2. Shrimp

In 2004, Switzerland ASL developed the six rounds of the prototype vehicle called crab, which the bilateral double parallelogram rocker suspension is used [11]. Each side of the suspension is made up of two sets of the parallelogram secondary rocker hinged at the middle wheel and a main rocker. The pole of each set of the secondary rocker is connected with the wheel. The middle pole of secondary rocker is fixedly connected with the main rocker. The main rocker is connected to the vehicle body with a differential mechanism. As shown in Figure 3, the crab was crossing the vertical wall. The stability of this vehicle is good and the terrain adaptability is strong. The platform space of carrying is much better than the shrimp. But the suspension structure is still complex.

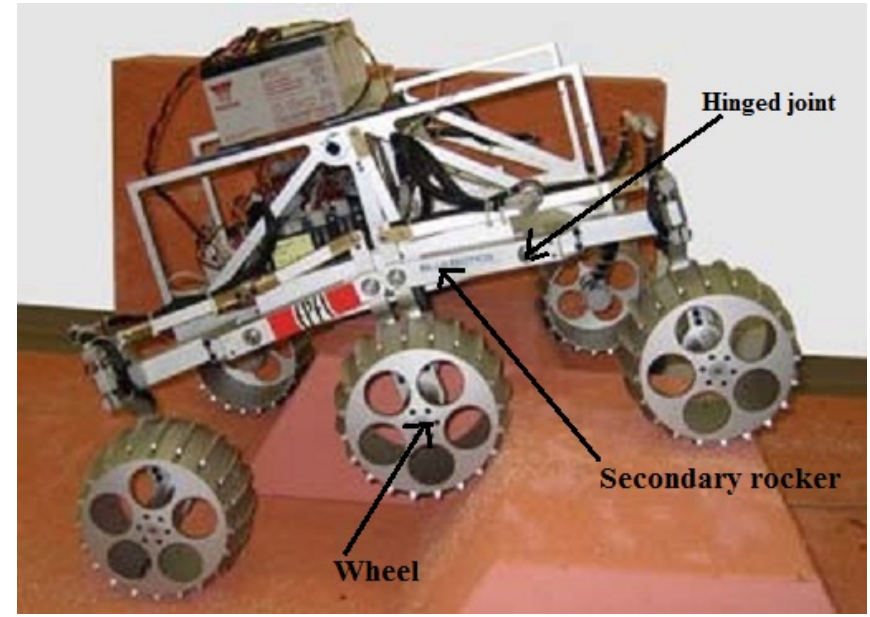

Fig.3. The six rounds of the prototype vehicle

\section{The Rocker-Bogie Suspension for the Planetary Rover Designed by American}

In 1987, JPL of NASA presented Rocky1 that is a principle prototype of a small six-wheel rover which firstly used the rocker-bogie suspension [12]. The wheel diameter is $8 \mathrm{~cm}$. The wheel grounding distance at the same side is identical. Each wheel can be independent drove. The part between the rear wheel and free hinged joint is the main rocker. The part between the front wheel and free hinged joint is the secondary rocker. The height of free hinged joint is higher than the axis of the wheel. As it was showed in Figure 4, the rover was traveling through an obstacle without any problem. This experience revealed that the negotiation ability and the trafficability of this rover is strong. The rotation angle of main rocker cannot be very big due to the limitation of the suspension structure.

Later, JPL developed lots of rovers. The Rocky 8 is the newest rover [13]. The weight reached up $30 \mathrm{~kg}$ (Showed in Figure 5). The wheel grounding distance at the same side is also identical. Each 
wheel can be also independent drove. The height of free hinged joint is also higher than the axis of the wheel. The Rocky 8 can carry more valid loading weight. It can travel at a long distance and avid obstacles.

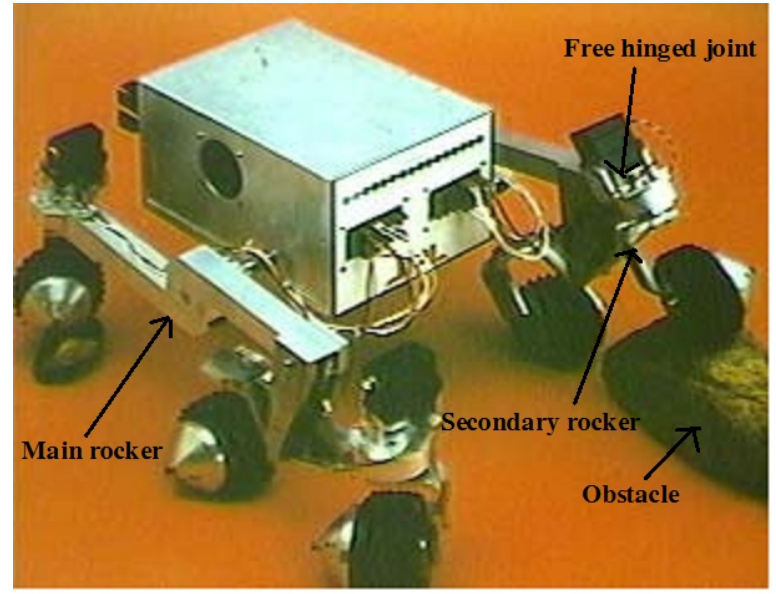

Fig.4. Rocky 1

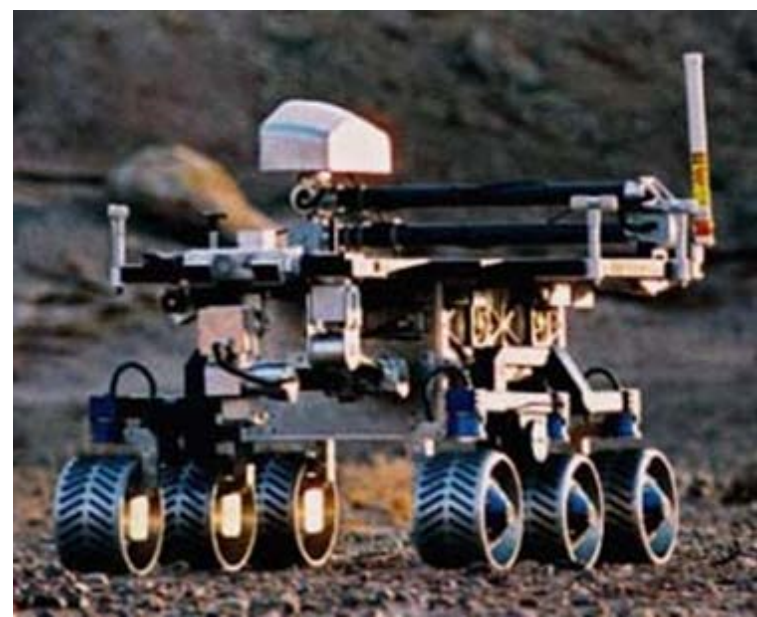

Fig.5. Rocky 8

Future combat system (FCS) designed by the U.S.Army combines many kinds of systems, which is a multifunction, networking, light and intelligentization weapon system [14]. This system is gradually equipped by the U.S.Army, as the technology matures. The robot vehicle is called mule as the main transport equipment of FCS, which is used to transport weapons, ammunitions and supplies for armys [15]. One mule can support two infantry classes and also can accompany them on the complex terrain. The primary mission of mules is transporting equipment and rucksacks about 900 1100 kg and transporting the wounded soldier to safe place.

From the Figure 6, it showed that the mule could travel on the complex terrain with high maneuverability. "Mule" was equipped with independent articulated suspension of $6 \times 6$ chassis. "Mule" used brake steering device and hybrid electric drive system. The hub of each tire is equipped with an electric motor. "Mule" has a high resistance to destruction. If a tire is damaged or destroyed, the remaining five tires still be able to maintain sufficient mobility. The height of obstacle which the mule can across reached $1.5 \mathrm{~m}$, which is much more than any other active wheeled or tracked vehicle equipped by the U.S. Army. The width of the trench which the mule can across reached $1.5 \mathrm{~m}$. The slope angle is more than 40 degrees. The wade depth is at least $1.25 \mathrm{~m}$.

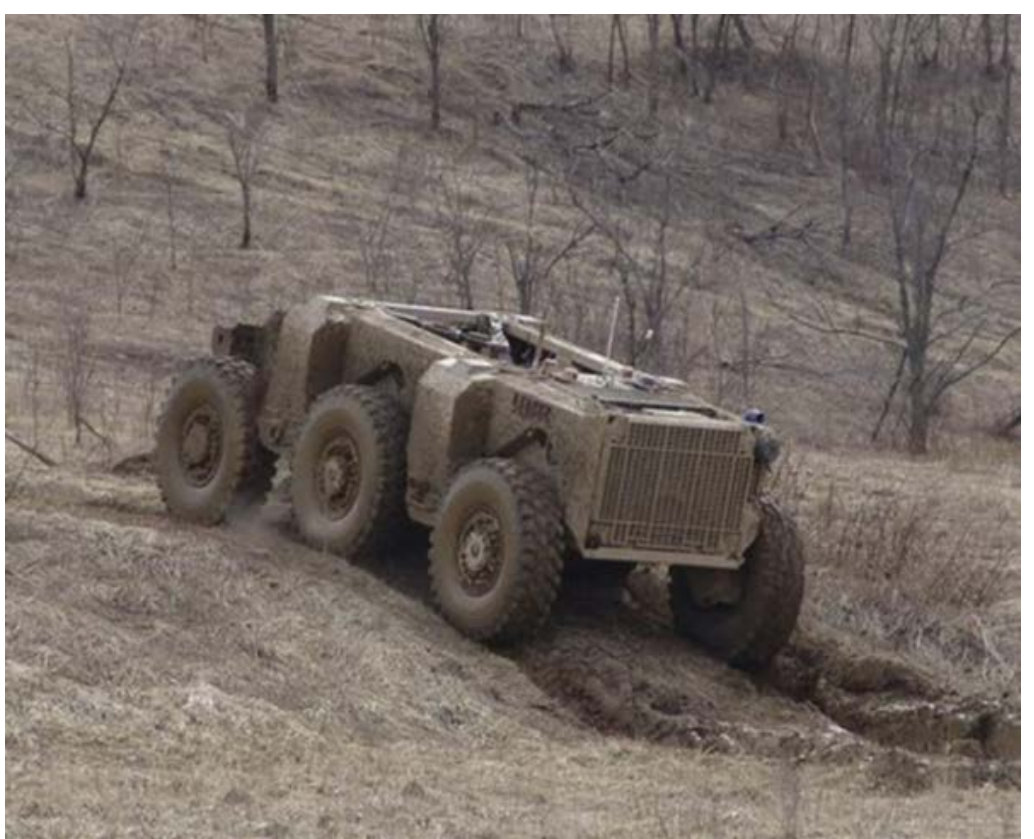

Fig.6. Mule 


\section{The Rocker-Bogie Suspension for the Planetary Rover Designed by Chinese}

National Defense University of Science and Technology designed a new type of folded-deployed suspension, known as the two-crank-slider suspension [16]. As shown in Figure 7, the left and right suspension is symmetrical and each suspension is composed of the main rocker, two cranks, two connecting rods, two slider and torsion bar spring. The left and right suspension is connected with differential mechanism through the spline. The middle of the differential mechanism is fixed to the body. Both side suspensions are rotatable relative to the vehicle body. Each wheel is driven by a wheel pump. But the crank rotation angle is limited.

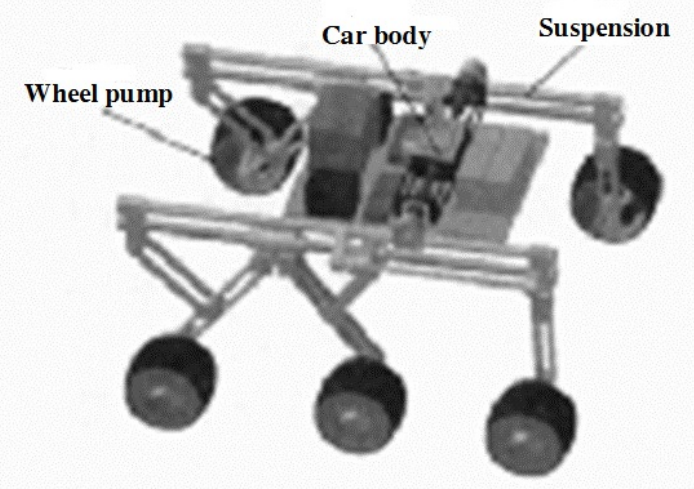

Fig.7. A new type of folded-deployed suspension

Harbin Institute of Technology developed the rocker-style inspection vehicles [17]. This suspension is similar to Rocky 1 . The auxiliary rocker can rotate around the hinge on the main rocker and The left and right main rocker arm can realize the differential movement around the differential mechanism so that the six wheels always touch the ground at the same time. In addition, the mobile sub-system consists of the 6 full-drive rounds. On the one hand, it increases adhesion and traction. On the other hand, if one or even two wheels fail to work, the remaining wheels continue to run. The rocker suspension and the differential mechanism are shown in Figs. 8 and 9, respectively.

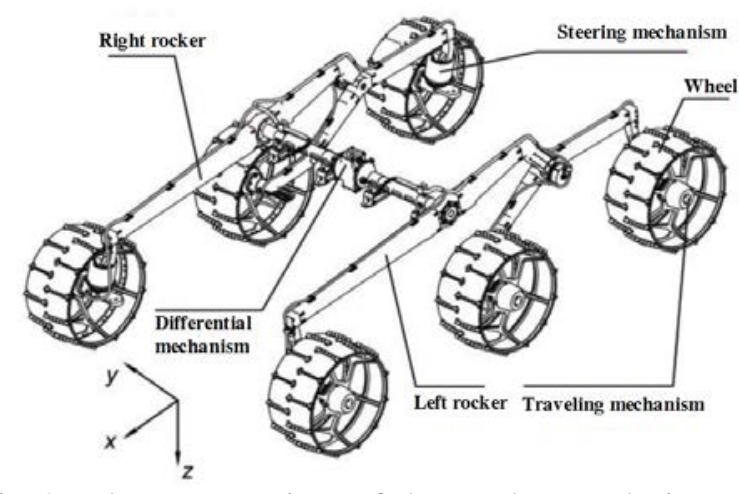

Fig.8. The suspension of the rocker-style inspection vehicles

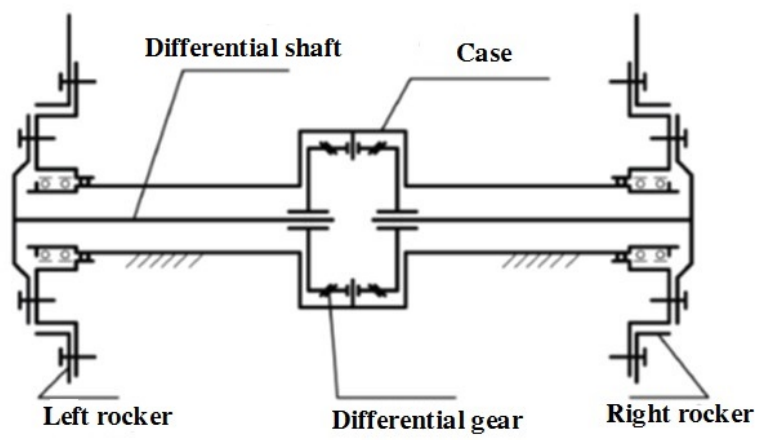

Fig. 9. The differential mechanism

\section{Conclusion}

As can be seen from the above analysis, rocker-type suspension originates in the earliest planetary vehicle. It is destined to can be only applied to small vehicles and low-speed vehicles. All of performances of the mule are excellent. Although the Mule is designed in accordance with the requirement of the high-speed vehicle. The FCS program has been stopped and the structure of the Mule may not be true. For the analysis of the disclosed structure, the suspension should be a single longitudinal arm, which cannot withstand a large lateral force when the vehicle is traveling at high speed. Therefore, when we develop a new generation of rocker suspension, although we can learn from existing research results and cannot completely copy. it should be based on the car suspension 
and be improved. At the same time, a new generation of rocker suspension should meet the requirements of high-speed vehicles.

\section{References}

[1] CABROL N A, CHONGDiAZ G, DOHM J M, et al. Atacama I: Science Results of the 1997 Nomad Rover Field Test in the Atacama Desert, Chile [C]. Proceedings of the Lun Planet Sci Conf, F, 1998

[2] HAYATI S, VOLPE R, BACKES P, et al. The Rocky 7 rover: a Mars sciencecraft prototype [C]. Proceedings of the IEEE International Conference on Robotics and Automation, 1997 Proceedings, F, 1997

[3] VOLPE R, BALARAM J, OHM T, et al. Rocky 7: a next generation Mars rover prototype [J]. Advanced Robotics, 1996 11(4) 341-358.

[4] ELLERY A. Environment-robot interaction-the basis for mobility in planetary micro-rovers [J]. Robotics \& Autonomous Systems, 2005 51(1) 29-39.

[5] SIEGWART R, LAMON P, ESTIER T, et al. Innovative design for wheeled locomotion in rough terrain [J]. Robotics \& Autonomous Systems, 2002 40(2-3) 151-62.

[6] Research Development of Deep Space Detection Vehicles and Lunar Rover of China [J]. 2009

[7] Kassel S. Lunokhod-1 Soviet Lunar Surface Vehicle[J]. Rand Corporation, 1971

[8] LINDROOS M. The Soviet Manned Lunar Program [M]. MIT Open Course Ware. 2011

[9] DUCROCQ A. Lunokhod-2. I(Translunar flight plan of Luna 21 probe, describing Lunokhod structure and lunar descent procedure) [J]. Air et Cosmos, 1973 44-47.

[10]SIEGWART R, LAMON P, ESTIER T, et al. Innovative design for wheeled locomotion in rough terrain [J]. Robotics and Autonomous systems, 2002 40(2) 151-62.

[11]THUEER T, KREBS A, SIEGWART R. Comprehensive locomotion performance evaluation of all-terrain robots; proceedings of the 2006 IEEE/RSJ International Conference on Intelligent Robots and Systems, F, 2006 [C]. IEEE.

[12]BICKLER D B. The new family of JPL planetary surface vehicles [J]. Missions Technologies \& Design of Planetary Mobile Vehicles, 1993 301-306.

[13]BACKES P G, NORRIS J S, POWELL M W, et al. Multi-mission activity planning for Mars lander and rover missions [J]. 2004 2(2)877-886.

[14]DIETTERLE R. The future combat systems (FCS) overview[C]. Proceedings of the Military Communications Conference, 2005 Milcom, F, 2005

[15]BYERS D B, BYERS D B. Multifunctional Utility/Logistics and Equipment (MULE) Vehicle Will Improve Soldier Mobility, Survivability and Lethality [J]. Army Al \& T, 2008

[16] SHANG J, LUO Z, ZHANG X, et al. Design and prototype development of a lunar rover with two-crank-slider suspension [J]. Zhongguo Jixie Gongcheng/China Mechanical Engineering, 2007 18(3) 348-51.

[17]TAO J G, LI J, LI B. Design of single drive folded-deployed suspension for six-wheeled rocker-bogie explore rover [J]. 2012 21-26. 